\title{
Optimal Route Maintenance based on Adaptive Equilibrium Optimization and GTA based Route Discovery Model in MANET
}

R Hemalatha ( $\square$ hemalathar.432@gmail.com )

Anna University Chennai

R Umamaheswari

Anna University Chennai

S Jothi

Anna University Chennai

Keywords:

Posted Date: April 21st, 2021

DOI: https://doi.org/10.21203/rs.3.rs-168239/v1

License: (c) (1) This work is licensed under a Creative Commons Attribution 4.0 International License.

Read Full License 


\section{Abstract}

The authors have requested that this preprint be removed from Research Square. 